\title{
Hybrid power plant for energy storage and peak shaving by liquefied oxygen and natural gas
}

\author{
Stefano Barsali, Alessio Ciambellotti, Romano Giglioli, Fabrizio Paganucci, Gianluca Pasini
}

\begin{abstract}
The increasing penetration of renewable energy sources in the electricity generation scenario forces to face new challenges to achieve an effective management of the power system both in technical and economic terms. Traditional energy storage solutions, like electrochemical cells and pumped hydro energy storage appear critical in terms of economic sustainability and site-dependency. The use of compressed air as energy storage has been investigated since the 20th century, but, in its first configuration, it was affected by site constraints as pumped hydro plants do. Liquid air energy storage has the chance to overcome those limits, but the experimental studies have far reached low efficiency. However, by rising the highest cycle temperature with the addiction of fossil fuel energy, these results can be largely improved.

The paper deals with the thermodynamic analysis of a hybrid system including energy storage and production based on a liquid air energy storage plant where only oxygen is liquefied, while liquefied natural gas is used as fuel. In the production phase, liquefied oxygen and natural gas react in an oxy-combustion chamber where a large amount of water is added to keep the temperature at an acceptable level by evaporation. The system does not require an external water supply since all the water needed is produced by the cycle itself, allowing the plant to be placed also in remote areas with poor water resources. At the beginning of the cycle, both the reagents are liquid at very low temperature (below $-150^{\circ} \mathrm{C}$ ) and they need heat to be gasified; a large amount of this heat can be recovered from the combustion products, which, being cooled at suitable pressure, release liquid carbon dioxide which can thus be easily separated. Optimized arrangements, compared to the performances of the best available hybrid peak plants, even with sufficiently conservative hypotheses, reach high equivalent round trip efficiencies, even higher than $90 \%$.
\end{abstract}

\section{Introduction}

Energy storage systems are becoming more and more important for power system operation with a continuously increasing share of generation from not dispatchable renewable sources. In 2016 more than a hundred billion dollars has been invested in PV based plants and a similar amount also in wind farms.

Hybrid systems for storage and generation of electricity help keeping the balance between power generation and demand in the electrical systems having a high share of production from variable and stochastic renewable sources (such as solar photovoltaics and wind), thus enabling the system to have a high energy and economic-financial effectiveness in providing the grid with regulation services [1], even in systems with load and generation uncertainty [2].

These systems, jointly managed with renewable generation, enable creating integrated systems able to follow a guaranteed production program and, therefore, to participate in the electricity market, overcoming the dispatching priority method used for subsidizing the generation from renewables.

Key features of these integrated hybrid systems can be:

- have a long-term electricity storage able to compensate the production surplus for at least one day (e.g. for a photovoltaic production system) or one week (e.g. for a wind power system), i.e. from ten to hundreds of equivalent running hours at rated power; 
- a high energy efficiency of the production subsystem, especially when fossil fuels are used.

Several different options exist for deploying large storage systems, mainly based on pumped hydroelectric storage, electrochemical storage and compressed air energy storage as shown in the review presented in [3]. Across the various technologies, electrochemical storage has probably the highest round-trip efficiency but cannot be economically used for charge-discharge cycles longer than some hours, since they show good performance mainly during cycles with a high power to energy ratio.

When dealing with longer cycles with daily or weekly storage, pumped hydro and compressed air are to be considered. Nowadays, more than $99 \%$ of the storage capacity available worldwide in power systems (excluded the fuel reservoir of thermal units) comes from pumped hydro energy storage (PHES) plants [3]. The most critical issue for these systems is finding a suitable location and, in developed countries, almost all technically and economically available sites have been used [4]. Compressed air energy storage has been widely studied during the $20^{\text {th }}$ century and two large plants were built in 1978 and 1991 . Although studies claims these systems have a high efficiency and several projects are being developed for further increasing their efficiency as presented in the detailed review reported in [5], finding suitable locations where a geological hermetic tank is available is a difficult task. High pressure and large volumes are needed for coping with a reasonable amount of stored energy. Studies performed in the ' 80 s have analysed the chance of using steel tanks for storing the compressed air but the relevant costs have resulted extremely high. In any case compressed air must be heated by an external source, before expanding for recovering the stored energy. Although the heat available during the air compression stage can in principle be stored and later used [5], this strategy poses quite critical issues, as plant size, cost and complexity.

In the last years, the use of the Liquid Air Energy Storage (LAES) technology has started to be more and more considered and investigated. Instead of being compressed at very high pressure, air is liquefied and stored in low pressure adiabatic tanks having a small size if compared to the volumes needed for compressed air energy storage (CAES). As a matter of fact, LAES specific energy is significantly higher (ranging between 150 and $250 \mathrm{Wh} / \mathrm{kg}$ ) with respect to CAES one $(30-60 \mathrm{Wh} / \mathrm{kg}$ ) [6]. Volume loss is limited to $0.05 \%$ per day [7]. Air is cooled down to $-195^{\circ} \mathrm{C}$ and liquefied using excess energy generation. When liquefied air needs to be used to recover the energy stored, it will be pressurized by means of a pump with a remarkable energy saving compared to gaseous air compression, then vaporised using the heat available at ambient temperature or with the help of a combustion process or even exploiting the residual heat of an industrial process. Mechanical work (and hence electrical energy) is obtained by air expansion in turbines.

One of the first papers presented on LAES is [8] where an interesting data on plant size is given comparing the reservoir needed for a 5 hour $50 \mathrm{MW}$ storage: it reports that $450000 \mathrm{~m}^{3}$ are needed with a $500 \mathrm{~m}$ drop for hydro storage, $120000 \mathrm{~m}^{3}$ at 80 bar for compressed air and just $1400 \mathrm{~m}^{3}$ for liquid air.

Some proposals foresee the adoption of thermal storage systems for improving the round trip efficiency of the plant. Heat is released during the liquefying process and reused during the air evaporation instead of an external source such as fossil fuel [9]. A comprehensive analysis is shown in [10] where a study indicates a maximum round trip efficiency of $86 \%$ can be achieved with ideal isothermal compression and expansion and without using fossil fuel. Accounting for real machine efficiencies, round trip efficiency drops below $50 \%$. Further studies with a Rankine cycle, give similar outcomes as shown in the works reported in [11], [12] and [13]. The efficiency of the liquefying process is the most critical issue and various solutions have been proposed for improving the round trip efficiency increasing the complexity of the cycle [6], or using cold 
liquefied natural gas as a cooling source [14], or by combining the needs for domestic cooling as presented in the three studies reported in [15], [16], [17].

Considering the results already presented in [4], and that liquid nitrogen and oxygen do not mix with each other with problems of stratification in cryogenic tanks, the proposal of this work is to use liquefied oxygen (LOx), instead of liquefied air, together with liquefied natural gas (LNG) used to increase the maximum cycle temperature and achieve the result that combustion products are just water and carbon dioxide. The liquid oxygen storage also needs less volume with respect to liquid air storage with benefit in terms of heat losses. Liquid water is used to keep the temperature of the oxy-combustion at reasonable values and the carbon dioxide in the exhaust is liquefied, at suitable pressure, by releasing the heat to the oxygen which needs to be evaporated.

The aim of the paper is to propose a new process and check its thermodynamic feasibility while assessing reasonable values for the efficiency the process might have. The process is optimized to get the maximum possible efficiency accounting for physical constraints and reasonable configuration and parameter choices. It is not intended to design a real plant and to simulate the actual cycle including detailed models of the components.

\section{Hybrid power system for electric energy storage and production}

The hybrid system taken as reference for the present study is shown in the block diagram of Figure 1

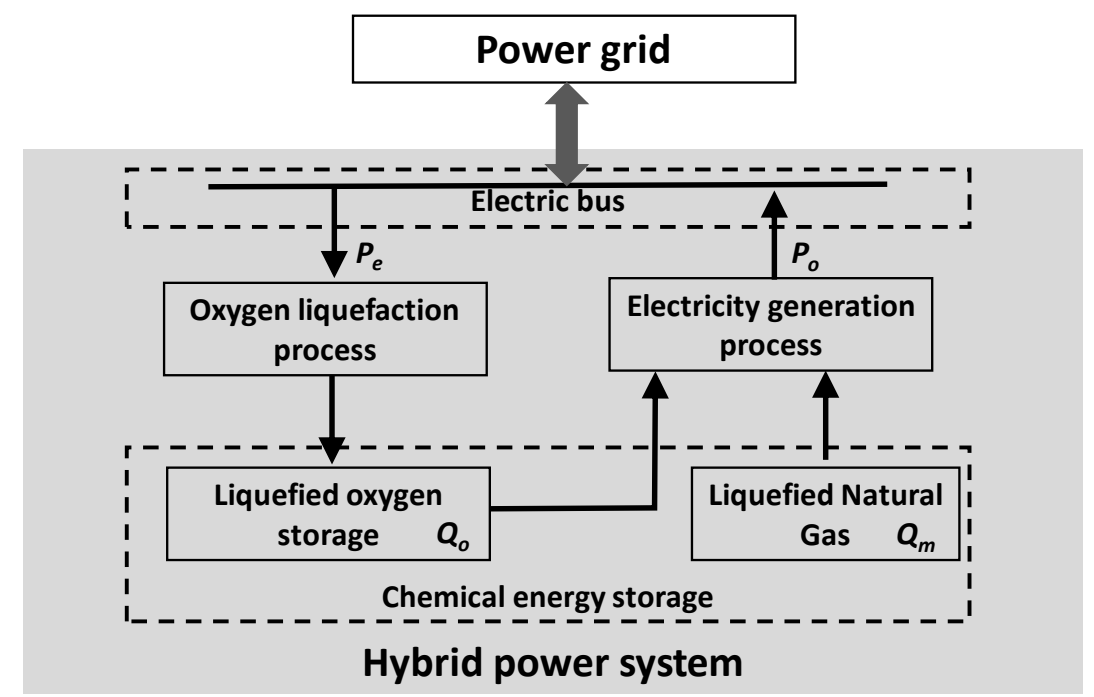

Figure 1. Principle scheme of the plant and rated characteristics

It can be characterized by the rated values of four variables:

- the rated power of the electricity generation system $\mathrm{P}_{\mathrm{e}}$,

- the rated power of the oxygen liquefaction process $P_{0}$,

- the mass quantities which can be stored in terms of liquid oxygen $Q_{0}$ and liquid methane $Q_{m}$.

It is clear that the maximum power exchanged with the network will be the maximum value between $\mathrm{Pe}_{\mathrm{e}}$ and Po.

The power values $P_{e}$ and $P_{o}$ will be determined on the basis of the management objectives of the hybrid system: 
- $P_{e}>P_{o}$ when the system is intended to be used for compensating short-term load peaks with the energy stored during long periods of excess production (for example, an excess of wind production during the night to be returned to cover the morning or evening peaks of the load),

- $P_{0}>P_{e}$ when the system is intended for absorbing short high production peaks not absorbed by the load and then returning the stored energy during a longer time at lower power (for example, a peak of photovoltaic production in the middle of the day not absorbed by the network due to lack of load to be used to supply a small load at night).

The amounts of LOx and LNG to be stored depend on:

- for liquid oxygen, the energy the hybrid system must absorb to store the overproduction. It depends upon the typical length of the generation cycle of renewable sources (for example one day for photovoltaic plants, about one week for wind turbines),

- for the LNG, it is to be optimized in relation to the possible supply logistics in the geographical air where the hybrid system is built.

However, since the thermodynamic analysis presented is aimed at maximizing the round-trip efficiency of the system and scale effects are not considered, the sizing of the hybrid plant is out of the scope of this work. The analysis can then be carried out in terms of specific quantities, intended as extensive variables referred to one kilogram of liquefied oxygen produced in the storage phase, having assumed an efficiency in line with the state of the art technology for its production. Anyway, considering the influence of the scale effect on the lower sizes, this analysis could be considered valid for plants having power in the range between 10 and $100 \mathrm{MW}$. These sizes can be profitably used jointly with large solar and wind farm [18].

\section{Optimization of the electricity production process}

The study is focused on the optimization of the electricity production process starting from the liquefied oxygen and liquefied natural gas stored in standard reservoirs. The process for liquefied oxygen production is not the target for the optimization, as the cryogenic gas industry already offers liquefying plants reaching very high efficiencies with well consolidated plant structure and cycle choices. Reasonable and conservative values are assumed in the study for considering the efficiency of these systems.

To assess the effectiveness of the system, a parameter must be defined to make a comparison with respect to a state of the art solution. In the existing solutions, such as a gas turbine and a storage system, the two plants are completely separated from each other; one is the generating unit, and the other is the storage system. They do not affect each other. In the innovative scheme proposed, an integrated system is considered, where the discharging phase of the liquefied oxygen storage is closely interacting with the liquefied natural gas combustion. It is therefore impossible to separately account for the generation and storage phases. A different way of assessing the efficiency is thus defined.

Energy input to the system comes in two shapes, the chemical energy of LNG and the energy spent for liquefying the oxygen. Considering a round trip period (RT), the fuel energy is given by:

$$
E_{\text {fuel }}=\int^{R T} q_{\text {fuel }}(t) L H V d t
$$

where $\mathrm{q}_{\mathrm{fuel}}$ is the fuel mass flow rate and LHV is its Lower Heating Value. The methane content in LNG ranges from $99.7 \%$ to $85 \%$ [19]. Depending on the origin of the natural gas used, the remainder (between $0.3 \%$ and $15 \%$ ) is made of other hydrocarbons which contribute to the total lower heat value similarly to pure 
methane. Only a negligible amount of nitrogen can be present and does not significantly affect the Wobbe index [19]. Carbon dioxide, if present in the gas, is completely separated by the liquefying process. In the analysis, also considering the accuracy needed for a first assessment of the proposed scheme, LNG has thus been approximated as composed by pure methane and a LHV of $50 \mathrm{MJ} / \mathrm{kg}$ has been assumed.

If we consider the possibility to directly exploit the fuel for electricity production, we can consider a state of the art gas turbine (TG) to be used for peak operation with an efficiency $\eta_{T G}$ of $38 \%$ when considering large heavy duty units. When looking at small (few tens of MW) aero derivative TG units, efficiency hardly exceeds $30 \%$. In this analysis a $38 \%$ efficiency is considered, and the results demonstrate that the system is energyeffective even compared to large units. For a complete round trip cycle the value ETG given by:

$$
E_{T G}=\int^{R T} q_{\text {fuel }}(t) L H V \eta_{T G} d t
$$

can therefore be defined as the energy that a generating unit would produce using the same amount of fuel. Although the definition has a general validity, both LHV and $\eta_{T G}$ are considered to be constant during a round trip.

Still for a complete round trip the value:

$$
E_{O 2}=\int^{R T} q_{O 2}(t) e_{O 2} d t
$$

represents the electrical energy used to produce the liquefied oxygen. In the equation qo2 $(\mathrm{t})$ is the mass flow rate of oxygen, while eo2 is the specific energy needed for liquefying oxygen from air at standard ambient condition. It is assumed to be $0.5 \mathrm{kWh}$ per $\mathrm{kg}$ of $\mathrm{O}_{2}$. Although lower values can be found in literature [20], the value of $0.5 \mathrm{kWh} / \mathrm{kg}$ is considered reasonable as it is confirmed by operators in the cryogenic industry as a conservative hypothesis. If lower values could be achieved, the system performance and efficiency would be largely improved.

The third element to be introduced, is the energy released to the grid during a round trip, which is the integral of the net electrical power produced $\left(\mathrm{P}_{\mathrm{e}}\right)$ :

$$
E_{G}=\int^{R T} P_{e}(t) d t
$$

The electrical efficiency in exploiting the fuel can thus be calculated by simply applying the first thermodynamic principle, considering the energy exchanged in a round trip period, as:

$$
\eta=\frac{E_{G}-E_{O 2}}{E_{\text {fuel }}}
$$

However, this parameter does not give enough information to assess whether the system is effective compared to the simple separate use of the TG unit and some other kind of storage, since the two processes are closely integrated in the proposed scheme and affect each other's efficiency.

A more representative figure of merit can be introduced considering the surplus energy released by the system thanks to the use of liquefied oxygen (again in a round trip) with respect to a state of the art TG and calculating the ratio between this surplus and the energy spent for producing the liquefied oxygen used. The surplus energy is thus given by:

$$
E_{\text {Gain }}=E_{G}-E_{T G}
$$

and an equivalent round trip efficiency of the storage can be defined as follows: 


$$
\eta_{R T}=\frac{E_{\text {Gain }}}{E_{O 2}}
$$

This parameter can profitably be used to compare the performance of this shape of storage with respect to other state of the art systems, such as batteries, PHES, CAES and others.

It is worth remarking that the value of surplus energy can be even greater than the energy spent for oxygen liquefaction, thus resulting in an equivalent round trip efficiency $\eta_{R T}$, defined as in (7), greater than one. This means that exploiting the liquid oxygen in the cycle enables increasing the efficiency of using the natural gas chemical energy compared to the use of a state of the art TG unit. Obviously the overall efficiency $\eta$, defined as in (5) will be lower than one. The so defined equivalent round trip efficiency is a measure of how the liquid oxygen storage performs.

To have a reference value for comparison, we can assume to use the same TG unit jointly with another shape of storage, not directly integrated in the cycle with the TG unit, such as a battery, a pumped hydro plant, or even a CAES. In that case the ratio $\eta_{R T}$ should be calculated as the actual ratio between the electrical energy released by the storage unit and the electrical energy needed for charging the storage itself. Typical values are in the range between $70 \%$ and $80 \%$. If the value calculated according to (7) for the proposed scheme is higher than these values, the scheme performance will be higher than state of the art solution. Results calculated below for different operating hypotheses show an equivalent round trip efficiency in the range between $82 \%$ and $104 \%$. All these configurations have therefore a better performance of a TG unit coupled with a standard storage system.

The result in terms of $\eta_{R T}$ are affected by the choice made for the efficiency of the reference TG plant $\eta_{T G}$, while $\eta$ remains unaffected. The higher the efficiency of the reference unit, the lower is the equivalent round trip efficiency of the proposed system. The validity of the use of the proposed solution will therefore depend upon the application which will be designed for. Today requests from system operators are for units able to quickly cover peak of demand or generation variation due to the stochastic behavior of renewable sources. The market is starting to offer systems of some MWs of rated power made of TG units jointly operating with a battery storage system to help exploiting renewable generation [18]. Therefore, typical values of TG units have been assumed as reference values.

Simulation and optimization are carried out with the commercial software Aspen Hysys, adopting the PengRobinson property package. It relies on the Peng-Robinson equation of state described in [21], suitable for predictions around and above the critical point. The package includes a feature $\left(\mathrm{CO}_{2}\right.$ Freeze Out) useful to indicate the formation of solid carbon dioxide. For performing the optimization, the included Box Optimization Scheme has been used, which is based on [22] and is a sequential search technique which solves problems with non-linear objective functions, subject to non-linear inequality constraints.

Inlet and outlet temperatures, intermediate pressure, backpressure and mass flows of fuel and water are the variables to be optimized in order to obtain the maximum RT efficiency. At the same time, the highest pressure, the highest temperature (in the combustion chambers), the maximum pinch point in the heat exchanger, and the condensing temperature are assumed as constraints to the optimization procedure. Some of these variables have been defined by iterating the optimization procedure using different values for those variables and checking the best compromise between efficiency and feasibility of the components.

The purpose of this study is not to make a detailed simulation of a real plant, but to assess the expected performances of the proposed scheme. The model includes the physical equations describing the different 
thermodynamic phases in the plant (compressions, expansions, combustion, heat exchanging) with reasonable hypotheses on the efficiency of the components which actually implement each single phase. Heat exchangers are simulated with the conservative assumptions of $20^{\circ} \mathrm{C}$ of pinch point temperature and 2 $\mathrm{kPa}$ of pressure drop, while, in the compression and expansion phases, the adiabatic efficiency is set to 0.85 for turbines, 0.80 for pumps and 0.75 for compressor. The assumptions made for describing the equilibrium of the system have been introduced by Peng and Robinson in [21] and are included in the tool used.

As the joint use of liquefied natural gas and liquefied oxygen is new for power generation applications, the authors chose to adopt basic principle schemes which still make possible understanding the whole process and being confident on the results achieved. So two schemes have been considered as reported in Figure 2 and Figure 4, the first being able to separate liquefied carbon dioxide. The thermodynamic cycles studied include advanced oxy-combustion starting from cryogenic products using two cascaded combustion chambers and recovering the heat available during the cycle with some properly sized heat exchangers.

In Figure 2 the scheme of the cycle is reported: liquefied natural gas and liquefied oxygen coming from cryogenic storage are pumped and re-gasified using waste heat, both reaching supercritical conditions (pressure and temperature over 90 bar and $0^{\circ} \mathrm{C}$ ). Such high pressure levels are reached using small amount of energy due to the liquid state of fuel and oxidant.

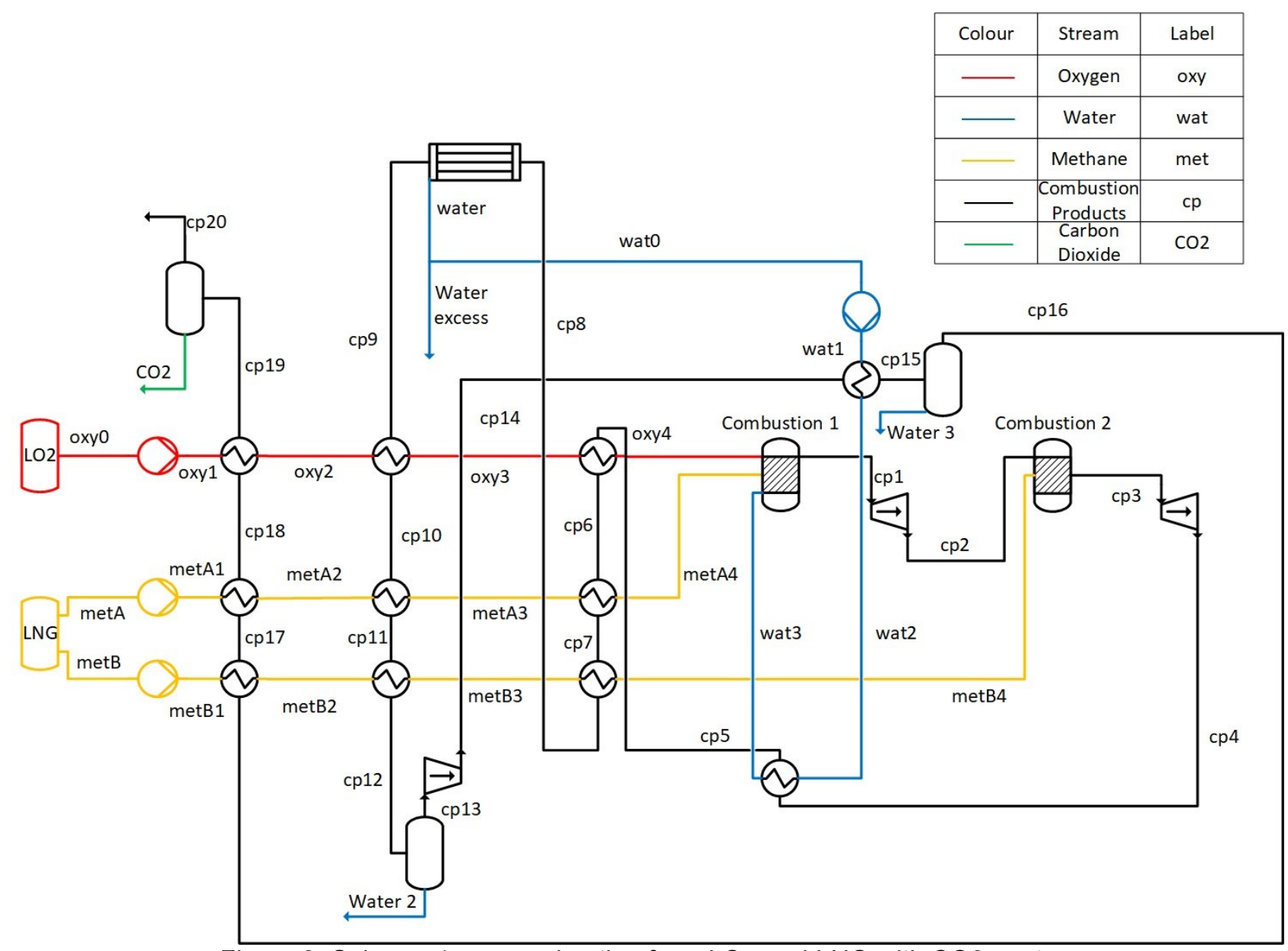

Figure 2. Scheme 1, oxycombustion from LOx and LNG with CO2 capture

As a first reasonable hypothesis, combustion is split in two different chambers, allowing the increase of the mean top temperature with great advantage in efficiency [20], [23] with respect to a single combustion phase. 
The whole oxygen stream is sent to the first combustion chamber, while the LNG stream is split for being injected in two combustion chambers. Also a certain amount of water is pumped to the first combustion chamber for inlet turbine temperature control. The whole oxygen passing through the first combustion chamber ensures a favourable excess of oxygen (also in the second combustion chamber an excess of $10 \%$ is still available) while the water increases the working flow across the turbines.

The water as temperature moderator is a better choice compared to the gaseous carbon dioxide because it does not require a compressor for being injected in the combustion chamber at the high pressure level needed (100 bar or more). On the other hand, at the end of the expansion, water needs that a large amount of heat is removed for being condensed and separated from the exhaust gases, due to the relatively high condensation heat at low pressure. The amount of heat needed (that is the water vaporisation heat) is higher for lower pressure levels. The study assumes two different temperatures of condensation $\left(30^{\circ} \mathrm{C}\right.$ and $\left.50^{\circ} \mathrm{C}\right)$, depending on the external cold source adopted (ambient air or water cooling). The temperature of $50^{\circ} \mathrm{C}$ for condensation is a usual value adopted for air cooled condensers. Lower temperature would require a larger condenser with increased costs and a cost effective solution is usually around $50^{\circ} \mathrm{C}$ as shown in [24]. When water cooling is used, the manufacturer specifications usually adopt a condensation temperature of $30^{\circ} \mathrm{C}$.

The first condenser separates $80 \%$ of total water only, leaving the remainder to be separated in the following stages.

The highest pressure in the cycle affects the overall efficiency, but the calculated optimized efficiency as a function of the highest pressure shows a saturation effect. The following Figure 3 shows how the calculated efficiency increases with the maximum system pressure while keeping all the other parameters constant. Since the system costs dependence upon pressure can be approximated by a logarithmic function as described in [25], the optimal value is near the knee of the curve, which is 150 bar. Calculations and results shown later in Table 1 also refer to the case of 100 bar to show the actual enhancement achieved at 150 bar.

This choice enables using mechanical components available on the market with a reasonable stress of the components. Similarly, the maximum temperature is fixed at $1000^{\circ} \mathrm{C}$ in the combustion chambers, assuming it as a reasonable target for oxy-combustion turbines [26].

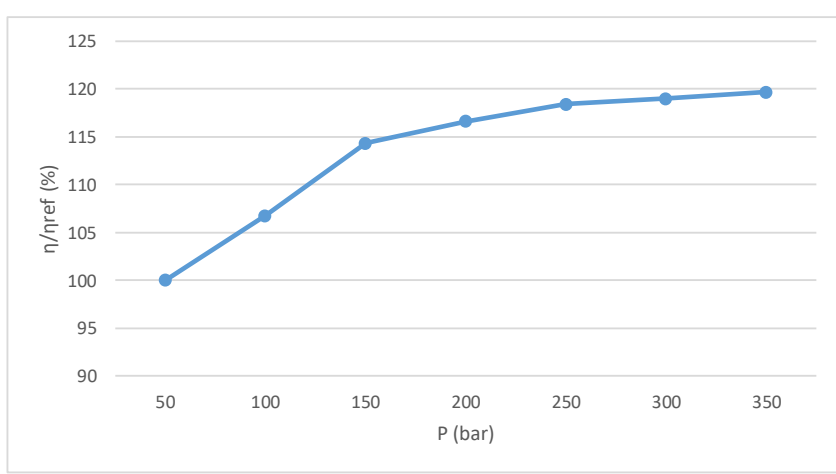

Figure 3. Percent increase of the system efficiency while increasing the maximum system pressure starting from the result achieved at 50bar as reference value

While passing through the heat exchanger, the exhaust gas stream allows LOx and LNG to be gasified and the high pressure water temperature to be raised above $200^{\circ} \mathrm{C}$. Hence the exhaust gases reach the condenser where all the water is separated and recycled. 
To support the choice of using no more than two combustion chambers, calculations have been repeated keeping the same operating conditions defined above (maximum combustion temperature of $1000{ }^{\circ} \mathrm{C}$, maximum pressure of 150 bar, condensation temperature of $30^{\circ} \mathrm{C}$ ) and the same hypotheses on the components using 1, 2 or 3 combustion chambers. The thermodynamic efficiency calculated as defined by equation (5) has resulted of $31 \%, 37 \%$ and $40 \%$ respectively. The second combustion chamber enables increasing the efficiency from $31 \%$ to $37 \%$, while the third would only make it rise from $37 \%$ to $40 \%$ with a noticeable increase of the plant complexity. For each combustion chamber added, also a new LNG compressing pump is needed, as well as two new heat exchangers and an expander.

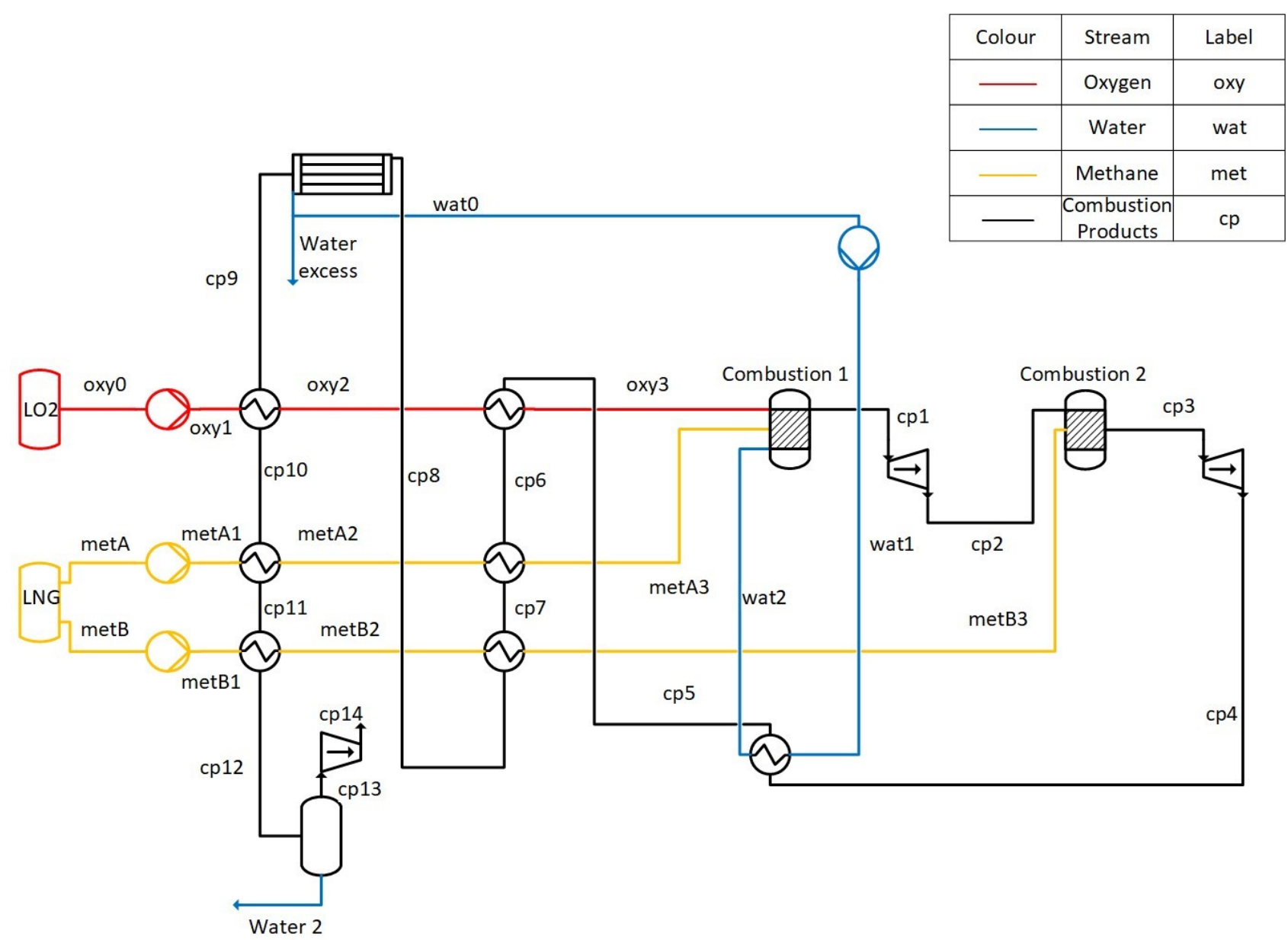

Figure 4. Scheme 2, oxycombustion from LOx and LNG without CO2 capture

In the second cycle, which does not include $\mathrm{CO}_{2}$ liquefaction (Scheme 2, Figure 4), exhaust gases are extracted to the open air using a compressor reaching the atmospheric pressure.

As shown in Figure 5, low pressure values do not allow for $\mathrm{CO}_{2}$ liquefaction. So, in Scheme 1, the above mentioned compressor increases pressure to 15 bar reaching a condition where liquefaction could take place at $-50^{\circ} \mathrm{C}$. 


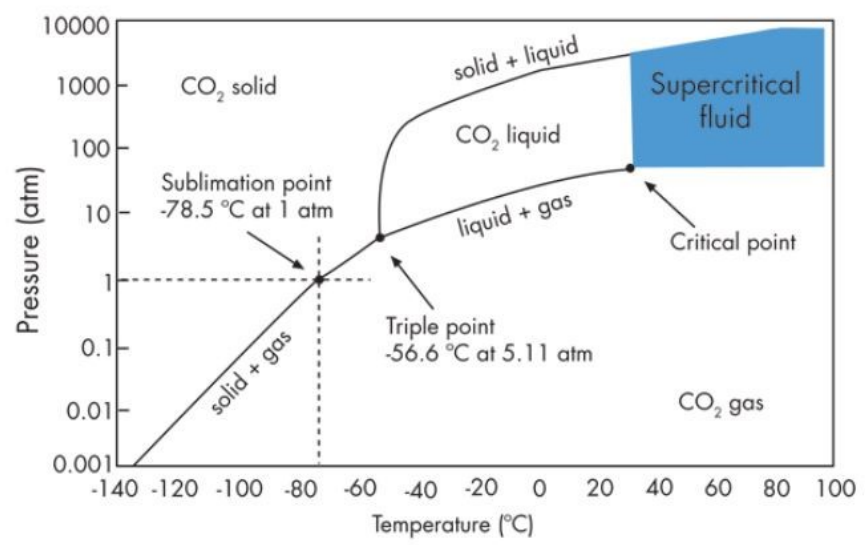

Figure 5. Phase diagram of $\mathrm{CO} 2$ [27]

Carbon dioxide liquefaction could be achieved using the latent heat of evaporation of LOx and LNG and their residual cold temperature after regasification. In the cycle of Scheme 1 , liquid $\mathrm{CO}_{2}$ is available for being separately stored.

Natural gas combustion also produces water, which has to be drained away in different condensation stages. An optimization has been conducted by varying the temperature at the output of the heat exchangers, the minimum expander pressure of discharge, the mass flow rate of water and LNG (excess of oxygen always guaranteed).

\section{Main results}

The main variables (mass flow rate, temperature, pressure and composition) at the points reported in Figure 2 and Figure 4 for the two cycles presented (Scheme 1 and 2), resulting from the simulations assuming 150 bar as high pressure and $30^{\circ} \mathrm{C}$ as condensation temperature, are listed in Appendix $\mathrm{A}$. The composition of the stream in the different sections of the plants, as finally reported in the tables, are the result of the chemical reactions (combustion) and physical transformations (condensation and separation) occurring in the components. In Scheme 1, starting from $1 \mathrm{~kg}$ of oxygen, $0.536 \mathrm{~kg}$ of water and $0.625 \mathrm{~kg}$ of liquid $\mathrm{CO}_{2}$ are produced, and eventually they must be put aside. The presence of a high amount of $\mathrm{CO}_{2}$ in combustion products (more than 14\%) keeps the working fluid away from the point of liquefaction, with beneficial effects for the expander.

Still referring to $1 \mathrm{~kg}$ of oxygen, $1.7 \mathrm{kWh}$ of electricity is generated in the first scheme and $1.8 \mathrm{kWh}$ in the second one. These are basic values for designing the oxygen storage, according to the kind of service to be provided.

The results achieved in terms of equivalent round trip efficiency as defined above are reported in Table 1. assuming two different values for the maximum pressure and for the condensation temperature. Better results are obtained with higher pressure and lower condensation temperature. 
Table 1 Equivalent round trip efficiency of scheme 1 and 2 as a function of maximum pressure and condensation temperature

\begin{tabular}{cc|cc} 
& \multicolumn{1}{c}{$\begin{array}{c}\text { Condensation } \\
\text { temperature }\left({ }^{\circ} \mathbf{C}\right)\end{array}$} & $\mathbf{1 0 0 ~ b a r}$ & $\mathbf{1 5 0}$ bar \\
\hline $\begin{array}{c}\text { Scheme 1 } \\
\text { (with carbon } \\
\text { capture) }\end{array}$ & $\mathbf{3 0}$ & $85 \%$ & $90.5 \%$ \\
\cline { 2 - 4 } & $\mathbf{5 0}$ & $82 \%$ & $87.5 \%$ \\
\hline $\begin{array}{c}\text { Scheme 2 } \\
\text { (without carbon } \\
\text { capture) }\end{array}$ & $\mathbf{3 0}$ & $97 \%$ & $104 \%$ \\
\cline { 2 - 4 } & $\mathbf{5 0}$ & $85.5 \%$ & $99.5 \%$
\end{tabular}

The equivalent round trip efficiency (7) ranges between $82 \%$ and $104 \%$. Obviously, this is not the measure of the efficiency in exploiting the energy entering the system in the shape of electricity used for liquefying the oxygen and of fuel energy content, which can be calculated according to the definition (5). It's worth remarking that this parameter shows how the use of liquefied oxygen helps exploiting the fuel energy with respect to a gas turbine. As reference, if the same energy was used in a system made by a separate TG unit and a storage, the calculation according to the definition of equation (7) would result in the cycle efficiency of the storage system used.

The $104 \%$ equivalent round trip efficiency shown by the best case means that the use of liquefied oxygen gives the chance for a better use of the fuel energy compared to the best available TG, equivalent to having a storage system capable of releasing even more energy than stored. Any result above the round trip efficiency of large storage plants (as LAES, CAES, PHES) means that the proposed arrangements have a better energy performance than the use of separate TG generation and storage systems.

In the best case, with a $104 \%$ equivalent round trip efficiency, the efficiency according to the first principle definition (5) is, in fact, $39 \%$, higher than $38 \%$ of the sole TG unit.

Not exploiting the cryogenic streams to liquefy the carbon dioxide yields only a little advantage for reducing the need of a water condenser and so the contribution to the improvement of the overall efficiency in scheme 2 (by recovering the waste heat) is small. For example, in a stream of $3.41 \mathrm{~kg} / \mathrm{h}$ of exhaust gas (coming from $1 \mathrm{~kg} / \mathrm{h}$ of liquefied oxygen) the water amounts to $2.8 \mathrm{~kg} / \mathrm{h}(80 \%)$ and, decreasing the temperature of this stream from $150^{\circ} \mathrm{C}$ down to $50^{\circ} \mathrm{C}$ (at $0.5 \mathrm{bar}$ ) to reach an adequate rate of separation requires about 7200 $\mathrm{kJ} / \mathrm{h}$. On the other side, $760 \mathrm{~kJ} / \mathrm{h}$ are needed to increase the temperature of the cryogenic fluids, vaporise and overheat them up to $150^{\circ} \mathrm{C}$, while the liquefaction of pure carbon dioxide at 10.5 bar (which is close to the partial pressure of $\mathrm{CO} 2$ after the compressor) needs about $320 \mathrm{~kJ} / \mathrm{h}$ and temperature below the $-38.8^{\circ} \mathrm{C}$. At the end of the process there is a little stream of oxygen and carbon dioxide almost in the same concentration: the excess of oxygen generates a biphasic mixture with $\mathrm{CO}_{2}$; the decreasing of molar concentration of $\mathrm{CO}_{2}$, due to its removal, will also decrease the $\mathrm{CO}_{2}$ partial pressure. In a hypothetical cycle with stoichiometric combustion we could reach a perfect $\mathrm{CO}_{2}$ separation, with a compressor pressure of 9 bar, thus resulting in a round-trip efficiency increase of $2 \%$.

Obviously, the inter-refrigeration of compression cp13-cp14 could improve the efficiency. Single compression needs more power but, however, the waste-heat is regenerated in the power cycle thank to the water (wat1wat2).

Pressure drops affect the efficiency ( $-3 \%$ with respect to the configuration without pressure losses) for the large number of heat exchangers. They decrease the condensation pressure and then the condensation temperature, increasing the waste heat at the condenser. 
The condenser necessarily requires a heat sink. If sea or river water could be used, a temperature of condensation of about $30^{\circ} \mathrm{C}$ could be achieved. Obviously, higher efficiencies are obtained with this temperature. However, accepting lower efficiency, the system can be installed in desert climate with air at about $40^{\circ} \mathrm{C}$ reaching condensation temperature of $50^{\circ} \mathrm{C}$. In this situation an air cooler could be designed with the correlation of Robinson and Briggs [28] to find the pressure drop and the power needed. To this regards, a preliminary estimation has been made for a $10 \mathrm{MW}$ plant. The air cooler requires a surface of $700 \mathrm{~m}^{2}$ and a power of $41 \mathrm{~kW}$, not significantly affecting the overall efficiency of the plant.

\section{Concluding remarks}

Even assuming state-of-the-art performance of the components, the analysis indicates the system exhibits a relatively high equivalent round trip efficiency, which represents how the energy stored in the liquid oxygen is exploited compared to state of the art systems. Values up to $104 \%$ are reached when working at 150 bar without carbon dioxide capture, meaning that the use of liquid oxygen also improves the efficiency of the use of the natural gas compared to a standard turbogas unit. An overall efficiency up to $39 \%$ is achieved in the use of the input energy. This outcome can be considered encouraging, and further and more accurate investigations worth to be performed. Concerning the phase of electrical power production, no significant improvements are expected with respect to the results obtained, unless significantly higher efficiencies of the components are considered. On the contrary, an increase of the equivalent round trip efficiency could come from an optimization of the liquefied oxygen production, where larger margins of improvement seem to be possible [20]; informal contacts with operators in the liquefied gas industry open interesting perspectives. To this regards it is necessary to perform a more detailed analysis taking into account plant size and duty cycle, as introduced in section 2. Moreover, the impact of transient operation of the plant, especially during liquid oxygen production, on round trip efficiency as well as plant management strategy, deserves to be investigated in detail to assess the real effectiveness of the proposed configuration as energy storage system.

The hybrid system proposed exhibits several interesting features which can be summarized as follows:

- State-of-the-art air separation units can be used for producing liquefied oxygen using low cost energy during the hours of exceeding generation;

- Liquefied natural gas is increasingly available on the market and its direct use as a liquid fuel strongly reduces the energy needed for compression;

- Oxy-combustion only produces carbon dioxide and water;

- Carbon dioxide can be easily liquefied, by removing the heat of vaporization using cold liquefied natural gas, and then submitted to a sequestration process.

Another peculiarity of the system which deserves to be highlighted, is that the plant can be completely autonomous with respect to water for cooling or for being used as the primary fluid of the thermodynamic cycle. Only liquefied natural gas needs to be provided if the air liquefying process is located inside the plant itself. Water can even be made available for local uses. The added value of these features might play an important role for ensuring a sustainable energy supply especially in remote areas where renewable sources are available. 
[1] S. Barsali, R. Giglioli, P. Pelacchi and D. Poli, "Hybrid energy systems for static applications," in 2016 IEEE AEIT International Annual Conference - Sustainable Development in the Mediterranean Area, Capri, Italy, 2016.

[2] D. Fioriti, R. Giglioli and D. Poli, "Short-term operation of a hybrid minigrid under load and renewable production uncertainty," in 2016 IEEE Global Humanitarian Technology Conference, GHTC 2016, Seattle, WA, USA, 2016.

[3] R. Amirante, E. Cassone, E. Distaso and P. Tamburrano, "Overview on recent developments in energy storage: Mechanical, electrochemical and hydrogen technologies," Energy Conversion and Management, vol. 132, pp. 372-387, 2017.

[4] M. Antonelli, S. Barsali, U. Desideri, R. Giglioli, F. Paganucci and G. Pasini, "Liquid air energy storage: Potential and challenges of hybrid power plants," Applied Energy, vol. 194, pp. 522-529, 2017.

[5] M. Budt, D. Wolf, R. Span and J. Yan, "A review on compressed air energy storage: Basic principles, past milestones and recent developments," Applied Energy, vol. 170, pp. 250-268, 2016.

[6] E. Borri, A. Tafone, A. Romagnoli and G. Comodi, "A preliminary study on the optimal configuration and operating range of a "microgrid scale" air liquefaction plant for Liquid Air Energy Storage," Energy Conversion and Management, vol. 143, pp. 275-285, 2017.

[7] R. Morgan, S. Nelmes, E. Gibson and G. Brett, "Liquid air energy storage - Analysis and first results from a pilot scale demonstration plant," Applied Energy, vol. 137, pp. 845-853, 2015.

[8] K. Chino and H. Araki, "Evaluation of energy storage method using liquid air," Heat transfer - Asian Research, vol. 29, no. 5, pp. 347-357, 2000.

[9] A. Sciacovelli, A. Vecchi and Y. Ding, "Liquid air energy storage (LAES) with packed bed cold thermal storage - From component to system level performance through dynamic modelling," Applied Energy, vol. 190, pp. 84-98, 2017.

[10] R. Morgan, "Liquid air energy storage - from theory to demonstration," International Journal of Environmental Studies, vol. 73, no. 3, pp. 469-480, 2016.

[11] B. Ameel, C. T'Joen, K. De Kerpel, P. De Jaeger, H. Huisseune, M. Van Belleghem and M. De Paepe, "Thermodynamic analysis of energy storage with a liquid air Rankine cycle," Applied Thermal Engineering, vol. 52, no. 1, pp. 130-140, 2013.

[12] G. L. Guizzi, M. Manno, L. M. Tolomei and R. M. Vitali, "Thermodynamic analysis of a liquid air energy storage system," Energy, vol. 93, no. 2, pp. 1639-1647, 2015.

[13] X. D. Xue, S. X. Wang, X. L. Zhang, C. Cui, L. B. Chen, Y. Zhou and J. J. Wang, "Thermodynamic analysis of a novel liquid air energy storage system," Physics Procedia, vol. 67, pp. 733-738, 2015.

[14] L. Luyao, W. Sixian, D. Zhang, Y. Luwei, Z. Yuan and W. Junjie, "Performance analysis of liquid air energy storage utilizing LNG cold energy," IOP Conference Series: Materials Science and Engineering,, vol. 171, 2017.

[15] G. Comodi, F. Carducci, J. Y. Sze, N. Balamurugan and A. Romagnoli, "Storing energy for cooling 
demand management in tropical climates: A techno-economic comparison between different energy storage technologies," Energy, vol. 121, pp. 676-694, 2017.

[16] A. Ahmad, R. Al-Dadah and S. Mahmoud, "Air conditioning and power generation for residential applications using liquid nitrogen," Applied Energy, vol. 184, pp. 630-640, 2016.

[17] A. Ahmad, R. Al-Dadah and S. Mahmoud, "Liquid nitrogen energy storage for air conditioning and power generation in domestic applications," Energy Conversion and Management, vol. 128, pp. 34-43, 2016.

[18] T. Kellner, "The Power Couple: This Battery And Jet Engine Hybrid Will Help California Grab More Renewables," GE Reports, 17 April 2017.

[19] A. Nicotra, "LNG, a Sustainable Fuel for all Transport Modes NGVA Europe," A position paper of NGVA Europe, p. 11.

[20] J. Wu, Y. Chen, Z. Zhu, X. Mei, S. Zhang and B. Zhang, "Performance simulation of NG/O2 combustion gas and steam mixture cycle with energy storage and CO2 capture," Applied Energy, vol. 196, pp. 6881, 2017.

[21] D.-Y. Peng and D. B. Robinson, "A new two-constant equation of state," Industrial and Engineering Chemistry Fundamentals, vol. 15, no. 1, pp. 59-64, 1976.

[22] M. Box, "A new method of constrained optimization and comparison with other methods," Computer Journal, no. 8, pp. 42-52, 1965.

[23] Y. Chen, Z. Zhu, J. Wu, S. Yang and B. Zhang, "A novel LNG/O2 combustion gas and steam mixture cycle with energy storage and CO2 capture," Energy, vol. 120, pp. 128-137, 2017.

[24] H. Zhai and E. S. Rubin, "Performance and cost of wet and dry cooling systems for pulverized coal power plants with and without carbon capture and storage," Energy Policy, vol. 38, no. 10, pp. 56535660, 2010.

[25] R. Turton, R. C. Bailie, W. B. Whiting, J. A. Shaeiwitz and D. Bhattacharyya, Analysis, syntesis and design of chemical processes, Pearson, 2012.

[26] R. E. Anderson, S. Mc Adam, F. Viteri, D. O. Davies, J. P. Downs and A. Paliszewski, "Adapting gas turbines to zero emission oxy-fuel power plants," in ASME Turbo Expo 2008: Power for Land, Sea and Air, Berlin, Germany, 2008, June 9-13.

[27] L. Hunter, "CO2 flow measurement key in CCS schemes," Power Engineering International (Pei), 01 april 2010.

[28] A. Bejan and A. Kraus, Heat transfer handbook, Wiley, 2003.

[29] D. Y. C. Leung, G. Caramanna and M. Maroto-Valer, "An overview of current status of carbon dioxide capture and storage technologies," Renewable and Sustainable Energy Reviews, vol. 39, pp. 426-443, 2014.

\section{Appendix A}

Tables 2 and 3 show the fluid properties the various points relevant to for Schemes 1 and 2 respectively, having adopted 150 bar as high pressure value and $30^{\circ} \mathrm{C}$ as condensation temperature. Results are 
obtained by means of the software Aspen Hysys (version 8.8) choosing Peng-Robinson as property package and considering oxygen $\left(\mathrm{O}_{2}\right)$, methane $\left(\mathrm{CH}_{4}\right)$, water $\left(\mathrm{H}_{2} \mathrm{O}\right)$ and carbon dioxide $\left(\mathrm{CO}_{2}\right)$ as fluids involved in the processes.

The choice of the variables (except for those initially fixed) of temperature, pressure and mass flow rate relies on the optimization performed with the Box Optimization Scheme supported by the software. All results are reported assuming a reference oxygen mass flow of $1 \mathrm{~kg} / \mathrm{h}$.

Table 2 detailed conditions simulated for scheme 1. Cases with 150 bar of maximum pressure and $30^{\circ} \mathrm{C}$ of condensation temperature

Scheme 1

\begin{tabular}{|c|c|c|c|c|c|c|}
\hline & $\begin{array}{c}\text { Mass Flow } \\
{[\mathrm{kg} / \mathrm{h}]}\end{array}$ & $\begin{array}{l}\text { Temp } \\
{\left[{ }^{\circ} \mathrm{C}\right]}\end{array}$ & $\begin{array}{c}\text { Pressure } \\
\text { [bar] }\end{array}$ & & $\begin{array}{c}\text { Composition } \\
{[\% \text { mass }]}\end{array}$ & \\
\hline Oxy0 & 1 & -195 & 1.2 & & O2 100\% & \\
\hline Oxy1 & 1 & -189.6 & 150 & & O2 100\% & \\
\hline Oxy2 & 1 & -44.5 & 149.98 & & O2 100\% & \\
\hline Oxy3 & 1 & -43.9 & 149.96 & & O2 100\% & \\
\hline Oxy4 & 1 & 150 & 149.94 & & O2 100\% & \\
\hline MetA & 0.174 & -160 & 1.2 & & $\mathrm{CH} 4100 \%$ & \\
\hline MetA1 & 0.174 & -152.4 & 150 & & $\mathrm{CH} 4100 \%$ & \\
\hline MetA2 & 0.174 & -144.6 & 149.98 & & $\mathrm{CH} 4100 \%$ & \\
\hline MetA3 & 0.174 & -138.5 & 149.96 & & $\mathrm{CH} 4100 \%$ & \\
\hline MetA4 & 0.174 & 117.7 & 149.94 & & $\mathrm{CH} 4100 \%$ & \\
\hline MetB & 0.066 & -160 & 1.2 & & $\mathrm{CH} 4100 \%$ & \\
\hline MetB1 & 0.066 & -159.4 & 12.19 & & $\mathrm{CH} 4100 \%$ & \\
\hline MetB2 & 0.066 & -133.7 & 12.17 & & $\mathrm{CH} 4100 \%$ & \\
\hline MetB3 & 0.066 & -131.4 & 12.15 & & $\mathrm{CH} 4100 \%$ & \\
\hline MetB4 & 0.066 & 95 & 12.13 & & $\mathrm{CH} 4100 \%$ & \\
\hline Wat0 & 2.2 & 30 & 0.12 & & $\mathrm{H} 2 \mathrm{O} 100 \%$ & \\
\hline Wat1 & 2.2 & 31.1 & 150 & & $\mathrm{H} 2 \mathrm{O} 100 \%$ & \\
\hline Wat2 & 2.2 & 158 & 149.98 & & $\mathrm{H} 2 \mathrm{O} 100 \%$ & \\
\hline Wat3 & 2.2 & 288 & 149.96 & & $\mathrm{H} 2 \mathrm{O} 100 \%$ & \\
\hline Cp1 & 3.374 & 1001 & 149.94 & $\mathrm{H} 2 \mathrm{O} 76.80 \%$ & CO2 $14.18 \%$ & O2 9.02\% \\
\hline Cp2 & 3.374 & 568.1 & 12.19 & $\mathrm{H} 2 \mathrm{O} 76.80 \%$ & CO2 $14.18 \%$ & O2 $9.02 \%$ \\
\hline Cp3 & 3.44 & 1004 & 12.13 & $\mathrm{H} 2 \mathrm{O} 79.61 \%$ & CO2 $19.14 \%$ & O2 1.25\% \\
\hline Cp4 & 3.44 & 405.9 & 0.22 & $\mathrm{H} 2 \mathrm{O} 79.61 \%$ & CO2 $19.14 \%$ & O2 $1.25 \%$ \\
\hline Cp5 & 3.44 & 180.8 & 0.2 & $\mathrm{H} 2 \mathrm{O} 79.61 \%$ & CO2 $19.14 \%$ & O2 $1.25 \%$ \\
\hline Cp6 & 3.44 & 142.6 & 0.18 & $\mathrm{H} 2 \mathrm{O} 79.61 \%$ & CO2 $19.14 \%$ & O2 1.25\% \\
\hline $\mathrm{Cp} 7$ & 3.44 & 115.2 & 0.16 & $\mathrm{H} 2 \mathrm{O} 79.61 \%$ & CO2 $19.14 \%$ & O2 $1.25 \%$ \\
\hline Cp8 & 3.44 & 104.5 & 0.14 & $\mathrm{H} 2 \mathrm{O} 79.61 \%$ & CO2 $19.14 \%$ & O2 1.25\% \\
\hline Cp9 & 0.859 & 30 & 0.12 & CO2 $76.57 \%$ & $\mathrm{H} 2 \mathrm{O} 18.43 \%$ & O2 5\% \\
\hline Cp10 & 0.859 & 29 & 0.10 & CO2 $76.57 \%$ & $\mathrm{H} 2 \mathrm{O} 18.43 \%$ & O2 5\% \\
\hline Cp11 & 0.859 & 25 & 0.08 & CO2 $76.57 \%$ & $\mathrm{H} 2 \mathrm{O} 18.43 \%$ & O2 5\% \\
\hline Cp12 & 0.859 & 24.3 & 0.06 & CO2 $76.57 \%$ & $\mathrm{H} 2 \mathrm{O} 18.43 \%$ & O2 5\% \\
\hline Cp13* & II & II & $1 /$ & & II & \\
\hline Cp14 & 0.859 & 817.8 & 15 & CO2 $76.57 \%$ & $\mathrm{H} 2 \mathrm{O} 18.43 \%$ & $\mathrm{O} 25 \%$ \\
\hline Cp15 & 0.859 & 51.3 & 14.98 & CO2 $76.57 \%$ & $\mathrm{H} 2 \mathrm{O} 18.43 \%$ & $\mathrm{O} 25 \%$ \\
\hline Cp16 & 0.703 & 51.3 & 14.98 & CO2 93.44\% & O2 6.11\% & $\mathrm{H} 2 \mathrm{O} 0.44 \%$ \\
\hline Cp17 & 0.703 & 45 & 14.96 & CO2 93.44\% & O2 6.11\% & $\mathrm{H} 2 \mathrm{O} 0.44 \%$ \\
\hline Cp18 & 0.703 & 40 & 14.94 & CO2 93.44\% & O2 $6.11 \%$ & $\mathrm{H} 2 \mathrm{O} 0.44 \%$ \\
\hline Cp19 & 0.703 & -50 & 14.92 & CO2 93.44\% & O2 $6.11 \%$ & $\mathrm{H} 2 \mathrm{O} 0.44 \%$ \\
\hline Cp20 & 0.077 & -50 & 14.92 & CO2 55.79\% & O2 $44.2 \%$ & \\
\hline $\begin{array}{l}\text { Water } \\
\text { excess }\end{array}$ & 0.38 & 30 & 0.12 & & $\mathrm{H} 2 \mathrm{O} 100 \%$ & \\
\hline Liquid2 & 0.156 & 51.4 & 14.98 & & $\mathrm{H} 2 \mathrm{O} 100 \%$ & \\
\hline Liquid4 & 0.625 & -50 & 14.92 & & CO2 100\% & \\
\hline
\end{tabular}

Step $\mathrm{Cp} 13^{*}$ has been introduced because, in some conditions, a phase separation is required.

Pumps and compressor require, respectively, $6.5 \mathrm{~W}$ and $240 \mathrm{~W}$. Liquefaction rate reaches $95 \%$. 
Table 3 detailed conditions simulated for scheme 2. Cases with 150 bar of maximum pressure and $30^{\circ} \mathrm{C}$ of condensation temperature

Scheme 2

\begin{tabular}{|c|c|c|c|c|c|c|}
\hline & $\begin{array}{c}\text { Mass Flow } \\
{[\mathrm{kg} / \mathrm{s}]}\end{array}$ & $\begin{array}{c}\text { Temp } \\
{\left[{ }^{\circ} \mathrm{C}\right]}\end{array}$ & $\begin{array}{c}\text { Pressure } \\
\text { [bar] }\end{array}$ & & $\begin{array}{c}\text { Composition } \\
\text { [\%mass] }\end{array}$ & \\
\hline Oxy0 & 1 & -195 & 1.2 & & O2 100\% & \\
\hline Oxy1 & 1 & -189.6 & 150 & & O2 100\% & \\
\hline Oxy2 & 1 & -144.3 & 149.98 & & O2 100\% & \\
\hline Oxy3 & 1 & 45 & 149.96 & & O2 100\% & \\
\hline MetA & 0.177 & -160 & 1.2 & & $\mathrm{CH} 4100 \%$ & \\
\hline MetA1 & 0.177 & -152.4 & 150 & & $\mathrm{CH} 4100 \%$ & \\
\hline MetA2 & 0.177 & -103.2 & 149.98 & & $\mathrm{CH} 4100 \%$ & \\
\hline MetA3 & 0.177 & 45 & 149.96 & & $\mathrm{CH} 4100 \%$ & \\
\hline MetB & 0.066 & -160 & 1.2 & & $\mathrm{CH} 4100 \%$ & \\
\hline MetB1 & 0.066 & -159.5 & 10.92 & & $\mathrm{CH} 4100 \%$ & \\
\hline MetB2 & 0.066 & -125.4 & 10.90 & & $\mathrm{CH} 4100 \%$ & \\
\hline MetB3 & 0.066 & 45 & 10.88 & & $\mathrm{CH} 4100 \%$ & \\
\hline Wat0 & 2.676 & 30 & 0.26 & & $\mathrm{H} 2 \mathrm{O} 100 \%$ & \\
\hline Wat1 & 2.676 & 31.1 & 150 & & $\mathrm{H} 2 \mathrm{O} 100 \%$ & \\
\hline Wat2 & 2.676 & 276.8 & 149.98 & & $\mathrm{H} 2 \mathrm{O} 100 \%$ & \\
\hline Cp1 & 3.364 & 996.2 & 149.96 & $\mathrm{H} 2 \mathrm{O} 76.77 \%$ & CO2 $14.51 \%$ & O2 $8.72 \%$ \\
\hline Cp2 & 3.364 & 550 & 10.92 & $\mathrm{H} 2 \mathrm{O} 76.77 \%$ & CO2 $14.51 \%$ & O2 $8.72 \%$ \\
\hline Cp3 & 3.43 & 990.7 & 10.92 & $\mathrm{H} 2 \mathrm{O} 79.60 \%$ & CO2 $19.50 \%$ & O2 0.9\% \\
\hline Cp4 & 3.43 & 462.5 & 0.36 & $\mathrm{H} 2 \mathrm{O} 79.60 \%$ & CO2 $19.50 \%$ & O2 $0.9 \%$ \\
\hline Cp5 & 3.43 & 69.4 & 0.34 & $\mathrm{H} 2 \mathrm{O} 79.60 \%$ & CO2 $19.50 \%$ & O2 $0.9 \%$ \\
\hline Cp6 & 3.43 & 67.9 & 0.32 & $\mathrm{H} 2 \mathrm{O} 79.60 \%$ & CO2 $19.50 \%$ & O2 $0.9 \%$ \\
\hline $\mathrm{Cp} 7$ & 3.43 & 66.4 & 0.30 & $\mathrm{H} 2 \mathrm{O} 79.60 \%$ & CO2 19.50\% & O2 0.9\% \\
\hline Cp8 & 3.43 & 64.8 & 0.28 & $\mathrm{H} 2 \mathrm{O} 79.60 \%$ & CO2 $19.50 \%$ & O2 $0.9 \%$ \\
\hline Cp9 & 0.754 & 30 & 0.26 & CO2 $88.4 \%$ & $\mathrm{H} 2 \mathrm{O} 7.54 \%$ & O2 4.06\% \\
\hline Cp10 & 0.754 & 20 & 0.24 & CO2 88.4\% & $\mathrm{H} 2 \mathrm{O} 7.54 \%$ & O2 4.06\% \\
\hline Cp11 & 0.754 & 13 & 0.22 & CO2 88.4\% & $\mathrm{H} 2 \mathrm{O} 7.54 \%$ & O2 4.06\% \\
\hline Cp12 & 0.754 & 9.8 & 0.20 & CO2 88.4\% & $\mathrm{H} 2 \mathrm{O} 7.54 \%$ & O2 4.06\% \\
\hline Cp13 & 0.716 & 9.9 & 0.20 & CO2 93.1\% & O2 $4.28 \%$ & $\mathrm{H} 2 \mathrm{O} 2.62 \%$ \\
\hline Cp14 & 0.716 & 186.5 & 1.20 & CO2 93.1\% & O2 $4.28 \%$ & $\mathrm{H} 2 \mathrm{O} 2.62 \%$ \\
\hline $\begin{array}{l}\text { Water } \\
\text { excess }\end{array}$ & 0.48 & 30 & 0.26 & & $\mathrm{H} 2 \mathrm{O} 100 \%$ & \\
\hline Liquid2 & 0.038 & 9.9 & 0.20 & & $\mathrm{H} 2 \mathrm{O} 100 \%$ & \\
\hline
\end{tabular}

